crop's drug will be produced.

This year, the Assured Artemisinin Supply System (A2S2) initiative, supported by the international drug-purchasing facility UNITAID, began to give advance loans to the companies that extract artemisinin from plants, and to encourage drug firms to sign long-term contracts with them. About 10,000 hectares of Artemisia was planted this year, twice as much as in 2009. But recent floods in China and Vietnam, and a drought in East Africa, mean that yields of artemisinin for use in 2011 may be only two-thirds of what has been planted, says Cutler.

\section{Breeding boost}

Yields could be vastly improved by planting new Artemisia strains. On average, one kilogram of its dried leaves yields some 8 grams of artemisinin. But at the National Institute of Agricultural Botany in Cambridge, UK, researchers have used selective breeding to create hybrid plants that produce up to 24 grams, says Colin Hill, chair of an Artemisia breeding consortium supported by the UK Department for the Environment, Food and Rural Affairs. These plants are now being grown and harvested commercially in Madagascar, and trialled in South Africa, Uganda, Zimbabwe and the United States, as well as in Britain.

In an alternative approach, Ian Graham and colleagues at the University of York, UK, identified key Artemisia genes that could optimize agricultural yields, robustness or other desirable traits when the plant is grown in different areas of the globe (I. A. Graham et al. Science 327, 328-331; 2010). Graham says that the work has helped to create plants that produce up to $50 \%$ more artemisinin per kilogram of leaves than the best commercial variety. They expect to release seed to commercial growers in mid-2012.

Despite the advances in plant biotechnology, Keasling says that semi-synthetic artemisinin is still sorely needed. Although it began as a way to make the drug more cheaply, the mass-produced semi-synthetic will be no cheaper than the plant-derived version - partly because Sanofi-aventis does not want to undercut farmers. Instead, it will be used to smooth out the cycle of boom and bust in crop-based artemisinin supply. "A stable and adequate source of artemisinin would be fundamentally important," says Silvia Schwarte of the World Health Organization's malaria programme.

As Newman says: "If you suddenly need twice as much artemisinin, you just fire up another fermenter."

Richard Van Noorden

\title{
Sponge genome goes deep
}

With a simple body plan lacking organs, muscles and nerve cells, the sea sponge hardly seems a rich avenue for study. Yet this humble organism squats firmly at the doorway to one of life's great mysteries: the leap to multicellularity.

Telltale molecular fragments teased out of ancient sediment ${ }^{1}$ show that sponges existed some 635 million years ago - the oldest evidence for metazoans (multicellular animals) on Earth. Now, a draft genome sequence of the Great Barrier Reef demosponge (Amphimedon queenslandica), published in this issue ${ }^{2}$ (see page 720 ), offers a comprehensive look at the genetic mechanisms that first allowed individual cells to work together as parts of a larger whole. As an added benefit, this genome may shed light on how primitive animal cells first learned to cope with the enduring hazard of collective existence: cancer.

"As the earliest branching lineage from our last common ancestor, sponges can tell us a lot about what is needed to make an animal," says geneticist Mansi Srivastava, the paper's lead author, now a postdoc at the Massachusetts Institute of Technology in Cambridge.

With more than 18,000 individual genes, the sponge genome represents a diverse toolkit, coding for many processes that lay the foundations for more complex creatures. These include mechanisms for telling cells how to adhere to one another, grow in an organized fashion and recognize interlopers. The genome also includes analogues of genes that, in organisms with a neuromuscular system, code for muscle tissue and neurons.

According to Douglas Erwin, a palaeobiologist at the Smithsonian Institution in Washington DC, such complexity indicates that sponges must have descended from a more advanced ancestor than previously suspected. "This flies in the face of what we think of early metazoan evolution," says Erwin.

Charles Marshall, director of the University of California Museum of Paleontology in Berkeley, agrees. "It means there was an elaborate machinery in place that already had some function," he says. "What I want to know now is what were all these genes doing prior to the advent of sponge."

The analyses of Srivastava and her colleagues suggest that there was a crucial window, some 150 to 200 million years in duration, when the basics of multicellular life emerged. Nearly one-third of the genetic alterations that distinguish humans from their last common ancestor with singlecelled organisms took place during this period. These changes would have occurred within our sponge-like forebears.

The researchers also identified parts of the genome devoted to suppressing individual cells that multiply at the expense of the collective. The presence of such genes indicates that the battle to stop rogue cells - in other words, cancer - is as old as multicellularity itself. Such a link was recently hinted at by work showing that certain 'founder genes' that are associated

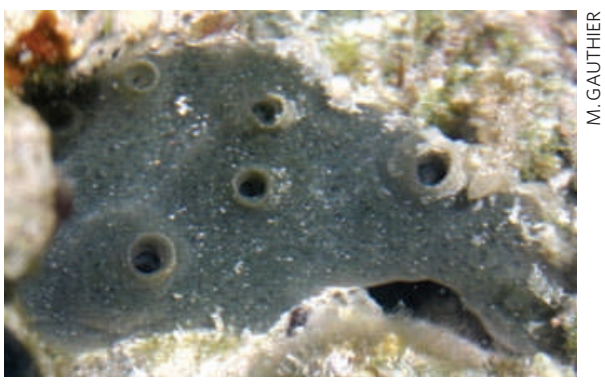

The genome of the demosponge $A$. queenslandica offers a glimpse at the dawn of multicellular life.

with human cancers first arose at about the same time as metazoans appeared ${ }^{3}$. The demosponge genome shows that genes for cell suicide - those activated within an individual cell when something goes wrong - evolved before pathways that are activated by adjacent cells to dispatch a cancerous neighbour.

"Cell suicide predated cell homicide," says Carlo Maley, an oncologist at the Wistar Institute in Philadelphia, Pennsylvania. This suggests that the single-celled colonial organisms that gave rise to our ancestors had already evolved mechanisms to kill themselves, which multicellular creatures later exploited as a cancer defence.

"Cancer was not the original motivation for this work," says Srivastava. "But now we can learn about the ways in which multicellular animals have to regulate themselves and the original function of these genes."

Adam Mann

1. Love, G. D. et al. Nature $457,718-721$ (2009)

2. Srivastava, M. et al. Nature 466, 720-726 (2010)

3. Domazet-Lošo, T. \& Tautz, D. BMC Biol. 8, 66 (2010). 